\title{
Predictive Value of Serum $\beta 2$-Microglobulin for Outcomes in Patients with Acute Respiratory Distress Syndrome Caused by Bacterial Infection
}

$\mathrm{Na}$ Cui

Beijing Chao-Yang Hospital

Xiaokai Feng

Beijing Chao-Yang Hospital

Chunguo Jiang

Beijing Chao-Yang Hospital

Jing Wang

Beijing Chao-Yang Hospital

Liming Zhang ( $\sim$ zhangliming@bjcyh.com )

Beijing Chao-Yang Hospital

\section{Research Article}

Keywords: Acute Respiratory Distress Syndrome, $\beta 2$-microglobulin, Mortality, Oxygenation

Posted Date: July 14th, 2021

DOI: https://doi.org/10.21203/rs.3.rs-668831/v1

License: (c) (1) This work is licensed under a Creative Commons Attribution 4.0 International License. Read Full License 


\section{Abstract \\ Background}

Acute respiratory distress syndrome (ARDS) is a heterogeneous disease with extremely high mortality. We hypothesized that the serum $\beta 2$-microglobulin ( $\beta 2 M G$ ) level would be elevated and be an independent risk factor for 28-day mortality in patients with ARDS.

\section{Methods}

We retrospectively enrolled 257 patients with ARDS caused by bacterial infection who were admitted consecutively into the Department of Pulmonary and Critical Care Medicine, Beijing Chao-Yang Hospital from January 1, 2015 to February 28, 2021. Patients were followed for up to 28 days from diagnosis and were divided into a survival group and non-survival group according to their clinical outcomes. The serum $\beta 2 M G$ levels and other clinical data were collected. The relationship between serum $\beta 2 M G$ levels and 28day mortality was explored by performing a Cox regression analysis adjusted for age, updated Charlson comorbidity index, disorders of consciousness, septic shock, albumin level, cardiac troponin I level, procalcitonin level, lactic acid level, prothrombin time, and partial pressure of arterial oxygen/fraction of inspired oxygen ratio.

\section{Results}

In this cohort, 161 patients survived, and 96 patients died within 28 days of diagnosis, yielding a 28-day mortality of $37.4 \%$. The median level of $\beta 2 \mathrm{MG}$ for all enrolled patients was 4.6 (interquartile range [IQR]: $2.9-8.5) \mathrm{mg} / \mathrm{L}$. Higher $\beta 2 \mathrm{MG}$ levels were significantly associated with 28-day mortality when the $\beta 2 \mathrm{MG}$ level was analysed as a continuous variable (hazard ratio [HR]: 1.050; $95 \%$ confidence interval [Cl]: $1.012-1.091 ; P=0.010)$ and when it was categorized into tertiles (HR: 1.482; 95\% Cl: 1.069-2.045; $P=$ 0.018). The serum $\beta 2 M G$ level exhibited a diagnostic accuracy for predicting mortality that was not inferior to those of the Acute Physiology and Chronic Health Evaluation score $(P=0.153)$ and Sequential Organ Failure Assessment score $(P=0.114)$.

\section{Conclusions}

The level of serum $\beta 2 \mathrm{MG}$ is elevated and is an independent risk factor of 28-day mortality in patients with ARDS, suggesting that it has predictive value for the outcomes of these patients.

\section{Background}

Acute respiratory distress syndrome (ARDS) is a heterogeneous disease process that may be triggered by a variety of direct or indirect pulmonary injuries, such as pneumonia, aspiration, chest trauma, sepsis, and 
acute pancreatitis. Despite the use of low tidal volume ventilation, conservative liquid strategies, and extracorporeal membrane oxygenation, the rate of mortality due to ARDS remains extremely high $[1,2]$. Early detection of prognostic risk factors is very important for reducing ARDS mortality. Numerous studies have attempted to define contributors to ARDS mortality, with conflicting results [1,3-6], which may be related to changes in clinical management strategy.

$\beta 2$-microglobulin ( $\beta 2 \mathrm{MG}$ ) is an 11.8-kDa, non-glycosylated polypeptide that is present in all nucleated cells [7]. As a low-molecular-weight protein, $\beta 2 M G$ is released into the circulation at a constant rate, freely filtered by the glomeruli, and completely reabsorbed and catabolized in the renal tubules. These properties may make it an ideal endogenous biomarker for estimating the glomerular filtration rate and acute kidney injury (AKI) [8-12]. Numerous studies have shown that the serum $\beta 2 M G$ level is not only used in assessing renal function by estimating the glomerular filtration rate and monitoring the effects of treatment $[13,14]$ but also associated with a number of clinical states, including chronic inflammatory diseases, malignancies, and adverse outcomes in exacerbated chronic obstructive pulmonary disease and critical illnesses [12,15-18]. ARDS is accompanied by an overwhelming inflammatory response and severe organ dysfunction, especially AKI. We hypothesized that for patients with ARDS, the serum B2MG levels would be elevated at the time of ARDS occurrence and would be related to poor prognosis.

\section{Methods}

\section{Ethical Approval}

This study was conducted in accordance with the 1964 Helsinki Declaration and its later amendments or comparable ethical standards and was approved by the Ethics Committee of the Beijing Chao-Yang Hospital, Capital Medical University (No. 2020-ke-429).

\section{Study Design and Population}

We retrospectively enrolled adult patients (aged $\geq 18$ years old) with ARDS (in accordance with the Berlin definition) [1] caused by bacterial infection who were admitted consecutively into the Department of Pulmonary and Critical Care Medicine, Beijing Chao-Yang Hospital from January 1, 2015 to February 28, 2021. Patients who lacked $\beta 2 M G$ data and patients with ARDS induced by causes other than bacterial infection were excluded. Other exclusion criteria included diseases that have a great impact on death, such as active malignant tumour, cerebral stroke, acute myocardial infarction, serious trauma, and a major operation (defined as lasting longer than 45 minutes) within the past month. Enrolled patients were followed for up to 28 days from diagnosis by the hospital electronic information system or by telephone and were divided into the survival group and non-survival group according to their clinical outcomes. A flow chart of patient enrolment and outcomes is shown in Fig. 1.

\section{Clinical Data Collection}


Data, which included demographic information, clinical history (medical history, exposure history, underlying comorbidities), symptoms, vital signs and laboratory findings within $24 \mathrm{~h}$ after ARDS diagnosis, treatments, complications, and patient survival at 28 days post-diagnosis, were collected from the medical records of the enrolled patients and analysed.

The concentrations of serum $\beta 2 M G$, serum creatinine (Scr), blood urea nitrogen (BUN), albumin, total bilirubin (TBIL), alanine aminotransferase (ALT), and fasting plasma glucose (FPG) were measured using Latex immune turbidity and Oxidase method by Beckman Coulter UniCel DXC800 (Beckman Coulter, Inc., USA). The levels of N-terminal pro-brain natriuretic peptide (NT-proBNP) and cardiac troponin I (cTnl) were measured by using a fluorescence immunoassay (TZ-310 Dry fluorescence immunoassay; ReLIA Biotechnologies Ltd., China). White blood cell (WBC) counts were performed by using an XT-1800i automatic haematology analyser (SYSMEX Co., Ltd, Japan). The C-reactive protein (CRP) levels were measured by using a solid-phase sandwich format immunometric assay by NycoCardTM READER II (Alere Technologies AS, Norway). The procalcitonin (PCT) levels were measured by performing an immunochromatographic assay by B.R.A.H.M.S GmbH (Thermo Fisher Scientific Inc., Germany). The prothrombin time (PT) was measured using a coagulation method by Instrumentation Laboratory (Wofen medical device Trading Co., Ltd, USA). The lactic acid level and partial pressure of arterial oxygen $\left(\mathrm{PaO}_{2}\right)$ were measured via spectrophotometry performed with an ABL90 blood gas analyser (Radiometer Medical ApS, Denmark). Body mass index (BMI) was calculated with the formula: $\mathrm{BMI}=$ weight $(\mathrm{kg}) / \mathrm{height}(\mathrm{m})^{2}$. We estimated the creatinine clearance rate $(\mathrm{Ccr})(\mathrm{mL} / \mathrm{min})$ with the Cockroft-Gault equation: $\mathrm{Ccr}=([140-$ age in years] $\times$ body weight in $\mathrm{kg}) /(72 \times \mathrm{Scr}$ in $\mathrm{mg} / \mathrm{dL})$. For women, the calculated values were multiplied by 0.85 .

\section{Definitions}

ARDS was defined as described in the Berlin definition [1]. Patients were divided into three groups according to their oxygenation levels [1]: (1) Mild: $200 \mathrm{mmHg}(1 \mathrm{mmHg}=0.133 \mathrm{kPa})<$ $\mathrm{PaO}_{2} / \mathrm{FiO}_{2}$ (fraction of inspired oxygen) $\leq 300 \mathrm{mmHg}$ with positive end-expiratory pressure (PEEP) or continuous positive airway pressure (CPAP) $\geq 5 \mathrm{cmH}_{2} \mathrm{O}\left(1 \mathrm{cmH}_{2} \mathrm{O}=0.098 \mathrm{kPa}\right)$; (2) Moderate: $100 \mathrm{mmHg}<\mathrm{PaO}_{2} / \mathrm{FiO}_{2} \leq 200 \mathrm{mmHg}$ with PEEP $\geq 5 \mathrm{cmH}_{2} \mathrm{O}$; and (3) Severe: $\mathrm{PaO}_{2} / \mathrm{FiO}_{2} \leq 100 \mathrm{mmHg}$ with PEEP $\geq 5 \mathrm{cmH}_{2} \mathrm{O}$. The severity of comorbid diseases, such as coronary heart disease, congestive heart failure, cerebrovascular disease, diabetes mellitus, dementia, connective tissue disease, liver disease, and kidney disease, was recorded and scored in accordance with the Charlson comorbidity index updated by Quan et al. (updated CCl) [19]. Disorders of consciousness were identified in accordance with the Glasgow Coma Scale [20]. Septic shock was defined in accordance with the Third International Consensus Definitions for Sepsis and Septic Shock (Sepsis-3) [21]. AKI was defined in accordance with the Kidney Disease: Improving Global Outcomes (KDIGO) clinical practice guidelines (i.e., Scr levels increased by $\geq 0.3 \mathrm{mg} / \mathrm{dL}$ ( $\geq 26.5 \mu \mathrm{mol} / \mathrm{L}$ ) within $48 \mathrm{~h}$ or by 1.5 times the baseline level within seven days) [22]. We applied the Acute Physiology and Chronic Health Evaluation (APACHE) II score and Sequential Organ Failure Assessment (SOFA) score to assess the disease severity [23, 24]. 


\section{Statistical Analyses}

Categorical variables are described as numbers and percentages (\%), and continuous variables are described as the mean and standard deviation (SD) or the median and interquartile range (IQR). The Shapiro-Wilk test was used to verify normality. Differences between the survival and non-survival groups were assessed by the two-sample $t$-test for normally distributed continuous variables, the Mann-Whitney $U$ test for non-normally distributed continuous variables, or the $\chi^{2}$ test for categorical variables. A Spearman rank correlation analysis was used to analyse the correlation between $\beta 2 M G$ levels and other basic variables. Both univariate and multivariate Cox regression analyses were applied to evaluate the relationship between risk factors and 28-day mortality. Results are presented as hazard ratios (HRs) with $95 \%$ confidence intervals (Cls). Serum $\beta 2 \mathrm{MG}$ levels were adjusted for age, updated $\mathrm{CCl}$, disturbance of consciousness, septic shock, serum albumin level, cTnl level, PCT level, PT, lactic acid level, and $\mathrm{PaO}_{2} / \mathrm{FiO}_{2}$ ratio in the multivariate Cox regression analysis. Survival rates grouped by $\beta 2 \mathrm{MG}$ tertile are presented as cumulative survival curves adjusted for the above-mentioned variables. Receiver operating characteristic (ROC) analyses were performed to calculate the sensitivity and specificity of risk factors for predicting 28-day mortality. The areas under receiver operating curves (ROC-AUCs) for different risk factors were compared using the method of DeLong et al. (1988) by MedCalc. All other statistical analyses were performed using SPSS version 21.0 (Statistical Package for the Social Sciences, Chicago, IL USA). All tests were two-tailed; differences with a value of $P<0.05$ were considered statistically significant.

\section{Results}

\section{Patient Enrolment}

A total of 257 patients with ARDS were included in this study. A flow chart of patient enrolment and outcomes is shown in Fig. 1.

\section{Characteristics of Survivors vs Non-survivors among Patients with ARDS}

Table 1 shows the demographic and clinical characteristics of the enrolled patients. In this cohort, 161 patients survived and 96 patients died within 28 days after the diagnosis of ARDS, yielding a 28-day mortality rate of $37.4 \%$. The median level of $\beta 2 M G$ for all patients with ARDS, regardless of their 28-day survival, was 4.6 (IQR: 2.9 - 8.5) $\mathrm{mg} / \mathrm{L}$. Compared with the non-survivors, the survivors were younger $(P=$ $0.002)$ and had lower updated CCls $(P<0.001)$, lower serum $\beta 2 \mathrm{MG}$ levels $(P<0.001)$, lower Scr levels $(P<$ $0.001)$, lower BUN levels $(P<0.001)$, lower cTnl levels $(P=0.001)$, lower NT-proBNP levels $(P<0.001)$, lower PCT levels $(P=0.008)$, lower lactic acid levels $(P<0.001)$, shorter PTs $(P=0.001)$, higher albumin levels $(P<0.001)$, and higher $\mathrm{PaO}_{2} / \mathrm{FiO}_{2}$ ratios $(P<0.001)$. Survivors also had lower APACHE II scores $(P<0.001)$ and lower SOFA scores $(P<0.001)$ than did non-survivors. More non-survivors than survivors had AKI $(P<0.001)$ or acute myocardial injury $(P=0.003)$. There was no difference in the duration of mechanical ventilation (MV) between survivors and non-survivors $(P=0.959)$. 


\section{Univariate and Multivariate Survival Analyses}

A univariate Cox regression analysis revealed that the level of serum $32 \mathrm{MG}$ is a predictor of 28-day mortality in patients with ARDS (HR: 1.096; 95\% Cl: 1.064 - 1.128; $P<0.001$ ) (Table 2). Other predictors of 28-day mortality in these patients included age, updated CCl, septic shock, Scr level, BUN level, Ccr, albumin level, PCT level, lactic acid level, $\mathrm{PT}, \mathrm{PaO}_{2} / \mathrm{FiO}_{2}$ ratio, APACHE II score, and SOFA score $(P<0.05$ for each).

To reduce data duplication, we did not include the APACHE II score or the SOFA score in our multivariate Cox proportional hazards analysis. Additionally, because we found that the serum $\beta 2 M G$ level was positively correlated with the Scr level (Spearman correlation coefficient: 0.815), the BUN level (Spearman correlation coefficient: 0.723 ), AKI (Spearman correlation coefficient: 0.683 ), and the NT-proBNP level (Spearman correlation coefficient: 0.564) and was negatively correlated with the Ccr (Spearman correlation coefficient: - 0.811 ) in our cohort ( $P<0.001$ for each) (Table 3$)$, we did not include these variables in the multivariate survival analysis either. The metabolism of NT-proBNP is influenced by renal function, and therefore we further analysed the correlation between the serum $32 \mathrm{MG}$ level and NT-proBNP level in patients with a Ccr of $>60 \mathrm{~mL} / \mathrm{min}$ and found a positive correlation between them (Spearman correlation coefficient: $0.338 ; P<0.001)$. Of the 257 patients in this study, $173(67.3 \%)$ had a CRP level equal to $120 \mathrm{mg} / \mathrm{mL}$ (the upper limit value for CRP testing in our laboratory at that time), and therefore we further analysed the 84 patients with a CRP level of $<120 \mathrm{mg} / \mathrm{mL}$ and found a significant positive correlation between the serum $\beta 2 \mathrm{MG}$ level and CRP level (Spearman correlation coefficient: $0.562 ; P<$ 0.001).

A higher $\beta 2 M G$ level was significantly associated with 28-day mortality after adjusting for age, updated $\mathrm{CCl}$, disorders of consciousness, septic shock, albumin level, cTnl level, PCT level, lactic acid level, PT, and $\mathrm{PaO}_{2} / \mathrm{FiO}_{2}$ ratio (HR: 1.050; 95\% Cl: 1.012 - 1.091; $P=0.010$ ) (Table 2).

When stratified by serum $32 \mathrm{MG}$ level tertiles, the 28-day mortality from the lowest to highest tertile was $12.5 \%(12 / 85), 38.5 \%(37 / 88)$, and $49.0 \%(47 / 84)$, respectively. The mortality risk was significantly higher in the highest category group (HR: $1.482 ; 95 \% \mathrm{Cl}: 1.069-2.045 ; P=0.018)$ after adjusting for age, updated $\mathrm{CCl}$, disorders of consciousness, septic shock, albumin level, CTnl level, PCT level, lactic acid level, $\mathrm{PT}$, and $\mathrm{PaO}_{2} / \mathrm{FiO}_{2}$ ratio (Fig. 2).

\section{The Prognostic Value of $\beta 2 M G$ Levels on 28-Day Mortality}

The serum $\beta 2 M G$ level showed a diagnostic accuracy for mortality prediction (AUC $=0.711 ; 95 \%$ Cl: 0.652 - 0.766 ; sensitivity: $76.0 \%$, specificity: $55.3 \% ; P<0.001$ ) superior to that of AKI (AUC $=0.620 ; 95 \%$ Cl: 0.558 - 0.680; sensitivity: 75.0\%, specificity: 49.1\%; $P<0.001 ; P=0.001$ for these two curves) and Ccr (AUC $=0.665 ; 95 \% \mathrm{Cl}: 0.604-0.723$; sensitivity: $66.7 \%$, specificity: $60.9 \% ; P<0.001 ; P=0.032$ for these two curves) and not inferior to that of the APACHE II score (AUC $=0.661 ; 95 \% \mathrm{Cl}$ : $0.599-0.718$; sensitivity: $71.9 \%$, specificity: $54.0 \% ; P<0.001 ; P=0.153$ for these two curves) or SOFA score (AUC = 
0.659; 95\% Cl: 0.598 - 0.717; sensitivity: $59.4 \%$, specificity: $65.8 \% ; P<0.001 ; P=0.114$ for these two curves) (Fig. 3), when the cut-off value for the $\beta 2 M G$ level was $4.0 \mathrm{mg} / \mathrm{L}$.

\section{Discussion}

Our study observed that the levels of $\beta 2 M G$ in patients with ARDS were elevated and were significantly higher in non-survivors than in survivors. A multivariate Cox proportional hazards analysis revealed that the $\beta 2 \mathrm{MG}$ level is an independent predictor for 28-day mortality in patients with ARDS, after adjusting for age, updated $\mathrm{CCl}$, disorders of consciousness, septic shock, albumin level, cTnl level, PCT level, PT, lactic acid level, and $\mathrm{PaO}_{2} / \mathrm{FiO}_{2}$ ratio. To our knowledge, this is the first report suggesting that the serum $\beta 2 \mathrm{MG}$ level might have a predictive value for the outcomes of patients with ARDS.

As a low molecular-weight protein, $\beta 2 \mathrm{MG}$ is an ideal endogenous biomarker for estimating the glomerular filtration rate and AKI $[8,12]$ and is also associated with a number of clinical states. Several previous studies have shown that levels of serum $\beta 2 M G$ are higher in patients with inflammatory bowel disease or systemic lupus erythematosus than in healthy controls, suggesting that it might also be a useful biomarker for the assessment of these autoimmune diseases [25, 26]. In addition, elevated levels of serum $32 \mathrm{MG}$ have been also observed in patients with haemato-oncological pathology and solid tumours despite their preserved renal function $[15,27]$. Some research has suggested that $\beta 2 M G$ is probably a general biomarker that reflects acute or chronic changes during inflammation and infection $[28,29]$. Levels of serum $\beta 2 M G$ are independently associated with major cardiovascular events in the general population as well as in patients with asymptomatic carotid atherosclerosis, patients with isolated systolic hypertension, and patients with acute heart failure who do not have severe renal insufficiency [10, 30-32]. Mao et al. reported that $\beta 2 M G$ levels are associated with poor outcomes in patients with exacerbated chronic obstructive pulmonary disease [18].

ARDS is a clinical syndrome with extremely high mortality, characterized by severe hypoxemia and an overwhelming inflammatory response, accompanied by multiple organ dysfunctions. Kohanpour et al. stated that an increase in serum $\beta 2 M G$ levels can occur with physical exercise under hypoxic conditions [33]. Hadzimuratovic et al. observed increased serum $\beta 2 M G$ levels in neonatal asphyxia [34]. These findings suggest that elevated serum $\beta 2 \mathrm{MG}$ levels are associated with hypoxemia. Some studies have found that an increase in serum $\beta 2 M G$ levels is also present during infectious diseases as well as in inflammatory responses $[28,29]$. In our study, the serum $\beta 2 M G$ levels were found to be elevated in patients with bacterial infection-induced ARDS. A rank correlation analysis revealed that the serum $\beta 2 \mathrm{MG}$ levels were negatively correlated with the $\mathrm{PaO}_{2} / \mathrm{FiO}_{2}$ ratio and positively correlated with the PCT and CRP levels. These correlations suggest that elevated serum $\beta 2 M G$ levels during ARDS may be associated with hypoxemia and infection as well as with inflammation. In addition, ARDS is often accompanied by multiple organ dysfunctions, such as AKI and myocardial injury, which are significantly associated with a poor prognosis in patients with ARDS $[35,36]$. Previous studies have shown that serum $\beta 2 M G$ levels are correlated with renal injury $[8,12]$ as well as with cardiac function $[32,37,38]$. Both AKI and myocardial injury were present in approximately half of the patients in our cohort, and our 
correlation analysis revealed that the serum $\beta 2 \mathrm{MG}$ levels are positively correlated with AKI, NT-proBNP levels, and cTnl levels and are negatively correlated with the Ccr and left ventricular ejection fraction. An analysis conducted after stratification of the patients according to their Ccrs [39] showed that serum $\beta 2 M G$ levels are also positively correlated with NT-proBNP levels in patients with a Ccr of $>60$ $\mathrm{mL} / \mathrm{min}$. These conditions suggest that, in the case of ARDS caused by bacterial infection, severe hypoxemia, infection, and inflammatory responses, as well as the impairment of organ function, result in increased $\beta 2 M G$ production and decreased renal filtration, ultimately leading to elevated serum $\beta 2 M G$ levels, which are positively correlated with disease severity and sensitively predict an elevated risk of death.

The ROC curves generated from our data show that the predictive value of serum $\beta 2 \mathrm{MG}$ levels for patient outcome is superior to that of $\mathrm{AKI}$ and $\mathrm{Ccr}$, which may additionally illustrate that the correlation between serum $\beta 2 M G$ levels and mortality is not solely a consequence of renal impairment. Further comparison of these ROC curves showed that serum $\beta 2 M G$ levels are not inferior to currently applied critical illness scores, such as the APACHE II score and SOFA score, for predicting 28-day mortality in patients with ARDS caused by bacterial infection. Therefore, the serum $\beta 2 M G$ level may be an ideal screening tool that can be reliably and cost effectively measured.

We applied the updated $\mathrm{CCl}$ [19] to assess patient comorbidities, including coronary heart disease, congestive heart failure, cerebrovascular disease, diabetes mellitus, dementia, connective tissue disease, liver disease, and kidney disease, and found it was significantly associated with 28-day mortality in patients with bacterial infection-induced ARDS. This result is consistent with previous research [40]. We also found that the lactic acid level was an independent risk factor for 28-day mortality in patients with bacterial infection-induced ARDS. Lactic acid is directly produced by anaerobic glucose metabolism and is the product of pyruvate transformation through glycolysis. An acceleration of lactate synthesis may be observed under conditions of increased glucose uptake from circulation, of increased glycogenolysis and glycolysis owing to enhanced epinephrine secretion, of inhibition of pyruvate dehydrogenase or of glycogen synthesis during sepsis and, finally, during tissue hypoxia. Therefore, the lactic acid level is considered to be a sensitive biomarker, which can reflect the oxygen supply in cells and the perfusion of surrounding tissues in the early stage of disease, and can be used to assess disease severity and to predict the occurrence of and death risk from septic shock and multiple organ dysfunction syndrome [21, 41]. Demirel reported that the lactate level is a good predictor of in-hospital mortality in pneumonia cases [42]. During ARDS, owing to severe hypoxemia and varying degrees of tissue perfusion insufficiency, glucose anaerobic metabolism increases, resulting in increased lactic acid production, which indicates a poor prognosis $[5,6]$.

Severe hypoxemia is a characteristic manifestation of ARDS. The $\mathrm{PaO}_{2} / \mathrm{FiO}_{2}$ ratio is an integral part of the assessment of patients with ARDS and is an important criterion for severity grading in the Berlin standard [1]. Although some studies have found that the $\mathrm{PaO}_{2} / \mathrm{FiO}_{2}$ ratio is not a good prognostic factor for ARDS [4], as an important indicator of the severity of lung injury, however, most studies have shown that the decreased $\mathrm{PaO}_{2} / \mathrm{FiO}_{2}$ ratio is associated with increased mortality or failure of non-invasive $\mathrm{MV}$ in 
patients with ARDS $[21,43,44]$. Similarly, our study showed that the $\mathrm{PaO}_{2} / \mathrm{FiO}_{2}$ ratio was a protective factor for the prognosis of patients with ARDS.

There are some limitations to our study. First of all, this research was conducted in a single centre, which could have biased its results. Second, owing to the small sample size in this study, to avoid overfitting, only a limited number of clinical variables were entered into the Cox regression analysis, and it is possible that potentially relevant variables were not evaluated. Third, owing to the retrospective nature of this study, we could not simultaneously assay the levels of $\beta 2 M G$ in the urine, and thus it was not possible to determine how much of the increase in serum $32 \mathrm{MG}$ levels can be attributed to renal injury and how much of the increased production is a consequence of the disease state. Fourth, although the ROC curve in our study showed predictive value for the outcome of patients with ARDS, we could not verify the applicability of this clinical indicator because of the small sample size. Future prospective studies will be necessary to identify and verify the prognostic value of serum $\beta 2 M G$ levels in patients with ARDS caused by bacterial infection.

\section{Conclusions}

This prospective study showed that the level of serum $32 \mathrm{MG}$, measured within 24 hours after the diagnosis of ARDS, was elevated and may be a promising early biomarker of adverse outcomes in patients with ARDS caused by bacterial infection. Further prospective research will be necessary to verify this finding, which may help clinicians undertake timely and effective programmes to improve the outcomes of these patients.

\section{Abbreviations}

ARDS, acute respiratory distress syndrome; $\beta 2 M G, \beta 2$-microglobulin; AKI, acute kidney injury; Scr, serum creatinine; BUN, blood urea nitrogen; TBIL, total bilirubin; ALT, alanine aminotransferase; FPG, fasting plasma glucose; NT-proBNP, N-terminal pro-brain natriuretic peptide; cTnl, cardiac troponin I; WBC, white blood cell; CRP, C-reactive protein; PCT, procalcitonin; PT, prothrombin time; BMI, body mass index; $\mathrm{Ccr}$, creatinine clearance rate; $\mathrm{PaO}_{2}$, partial pressure of arterial oxygen; $\mathrm{FiO}_{2}$, fraction of inspired oxygen; PEEP, positive end-expiratory pressure; CPAP, continuous positive airway pressure; $\mathrm{CCl}$, Charlson comorbidity index; APACHE, Acute Physiology and Chronic Health Evaluation; SOFA, Sequential Organ Failure Assessment; MV, mechanical ventilation; SD, standard deviation; IQR, interquartile range; HR, hazard ratio; $\mathrm{Cl}$, confidence interval; $\mathrm{ROC}$, receiver operating characteristic.

\section{Declarations}

\section{Acknowledgements}

Not applicable.

\section{Authors' contributions}


NC, JW and LMZ contributed to the conception and design of the study. LMZ and JW took part in managing the research. XKF and CGJ contributed to the acquisition of data. All authors were involved in data analysis and interpretation and development of the manuscript. All authors read and approved the final manuscript. LMZ and JW contributed equally to this article and shared corresponding authorship.

\section{Funding}

This research was supported by the multicenter clinical research verification of nasal high flow humidification oxygen therapy equipment (Grant NO. 2019YFC0121704 to Dr Jing Wang).

\section{Availability of data and materials}

All data analysed during the study are presented in the main manuscript. The anonymous dataset is available from the corresponding author upon reasonable request.

\section{Ethics and approval and consent to participate}

This retrospective study involving human participants was approved by the ethics committee of the Beijing Chao-Yang Hospital, Capital Medical University (2020-ke-429) and was in accordance with 1964 Helsinki Declaration and its later amendments or comparable ethical standards.

\section{Consent for publication}

Not applicable.

\section{Competing interests}

The authors declare that they have no competing interests.

\section{Author details}

${ }^{1}$ Department of Pulmonary and Critical Care Medicine, Beijing Chao-Yang Hospital, Capital Medical University, Beijing, 100020, People's Republic China; ${ }^{2}$ Beijing Institute of Respiratory Medicine, Beijing 100020, People's Republic China

\section{References}

1. ARDS Definition Task Force RV, Rubenfeld GD, Thompson BT, Ferguson ND, Caldwell E, Fan E, et al. Acute Respiratory Distress Syndrome: The Berlin Definition. JAMA. 2012; 307(23):2526-2533.

2. Bellani G, Laffey JG, Pham T, Fan E, Brochard L, Esteban A, et al. Epidemiology, Patterns of Care, and Mortality for Patients With Acute Respiratory Distress Syndrome in Intensive Care Units in 50 Countries. JAMA. 2016; 315(8):788-800.

3. Villar J, Ambrós A, Soler JA, Martínez D, Ferrando C, Solano R, et al. Age, PaO2/FIO2, and Plateau Pressure Score: A Proposal for a Simple Outcome Score in Patients With the Acute Respiratory 
Distress Syndrome. Crit Care Med. 2016; 44(7):1361-1369.

4. Chen WL, Lin WT, Kung SC, Lai CC, Chao CM. The Value of Oxygenation Saturation Index in Predicting the Outcomes of Patients with Acute Respiratory Distress Syndrome. J Clin Med. 2018; $7(8)$.

5. Kamo T, Tasaka S, Suzuki T, Asakura T, Suzuki S, Yagi K, et al. Prognostic values of the Berlin definition criteria, blood lactate level, and fibroproliferative changes on high-resolution computed tomography in ARDS patients. BMC Pulm Med. 2019; 19(1):37.

6. Deng XJ, Zou Y, Wu J, Liang Y, Gu SY. The effect of blood lactate and NT-proBNP predict the survival in patients with invasive mechanical ventilation. Ann Transl Med. 2020; 8(7):458.

7. Woitas RP, Stoffel-Wagner B, Poege U, Schiedermaier P, Spengler U, Sauerbruch T. Low-molecular weight proteins as markers for glomerular filtration rate. Clin Chem. 2001; 47(12):2179-2180.

8. Bianchi C, Donadio C, Tramonti G, Consani C, Lorusso P, Rossi G. Reappraisal of serum beta2microglobulin as marker of GFR. Ren Fail. 2001; 23(3-4):419-429.

9. Jovanović D, Krstivojević P, Obradović I, Durdević V, Dukanović L. Serum cystatin C and beta2microglobulin as markers of glomerular filtration rate. Ren Fail. 2003; 25(1):123-133.

10. Amighi J, Hoke M, Mlekusch W, Schlager O, Exner M, Haumer M, et al. Beta 2 microglobulin and the risk for cardiovascular events in patients with asymptomatic carotid atherosclerosis. Stroke. 2011; 42(7):1826-1833.

11. Zaleska-Kociecka M, Skrobisz A, Wojtkowska I, Grabowski M, Dabrowski M, Kusmierski K, et al. Serum beta-2 microglobulin levels for predicting acute kidney injury complicating aortic valve replacement. Interact Cardiovasc Thorac Surg. 2017; 25(4):533-540.

12. Wang $\mathrm{R}, \mathrm{Hu} \mathrm{H}, \mathrm{Hu} \mathrm{S}, \mathrm{He} \mathrm{H}$, Shui $\mathrm{H}$. $\beta 2$-microglobulin is an independent indicator of acute kidney injury and outcomes in patients with intracerebral hemorrhage. Medicine (Baltimore). 2020; 99(8):e19212.

13. Viberti GC, Keen H, Mackintosh D. Beta 2-microglobulinaemia: a sensitive index of diminishing renal function in diabetics. Br Med J (Clin Res Ed). 1981; 282(6258):95-98.

14. Inker LA, Tighiouart H, Coresh J, Foster MC, Anderson AH, Beck GJ, et al. GFR Estimation Using $\beta$ -

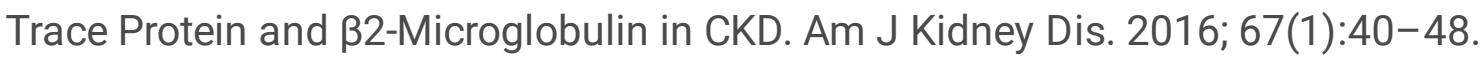

15. Bataille R, Durie BG, Grenier J. Serum beta2 microglobulin and survival duration in multiple myeloma: a simple reliable marker for staging. Br J Haematol. 1983; 55(3):439-447.

16. Cheung CL, Lam KS, Cheung BM. Serum $\beta-2$ microglobulin predicts mortality in people with diabetes. Eur J Endocrinol. 2013; 169(1):1-7.

17. Argyropoulos CP, Chen SS, Ng YH, Roumelioti ME, Shaffi K, Singh PP, et al. Rediscovering Beta-2 Microglobulin As a Biomarker across the Spectrum of Kidney Diseases. Front Med (Lausanne). 2017; 4:73.

18. Mao W, Wang J, Zhang L, Wang Y, Wang W, Zeng N, et al. Serum $\beta 2$-Microglobulin is Associated with Mortality in Hospitalized Patients with Exacerbated Chronic Obstructive Pulmonary Disease. Int J Chron Obstruct Pulmon Dis. 2020; 15:723-732. 
19. Quan H, Li B, Couris CM, Fushimi K, Graham P, Hider P, Januel JM, et al. Updating and validating the Charlson comorbidity index and score for risk adjustment in hospital discharge abstracts using data from 6 countries. Am J Epidemiol. 2011; 173(6):676-682.

20. Jones C. Glasgow coma scale. Am J Nurs. 1979; 79(9):1551-1553.

21. Singer M, Deutschman CS, Seymour CW, Shankar-Hari M, Annane D, Bauer M, et al. The Third International Consensus Definitions for Sepsis and Septic Shock (Sepsis-3). JAMA. 2016; 315(8):801-810.

22. Khwaja A. KDIGO clinical practice guidelines for acute kidney injury. Nephron Clin Pract. 2012; 120(4):c179-c184.

23. Knaus WA, Draper EA, Wagner DP, Zimmerman JE. APACHE II: a severity of disease classification system. Crit Care Med. 1985; 13(10):818-829.

24. Lambden S, Laterre PF, Levy MM, Francois B. The SOFA score-development, utility and challenges of accurate assessment in clinical trials. Crit Care. 2019; 23(1):374.

25. Kim HA, Jeon JY, Yoon JM, Suh CH. Beta 2-microglobulin can be a disease activity marker in systemic lupus erythematosus. Am J Med Sci. 2010; 339(4):337-340.

26. Yılmaz B, Köklü S, Yüksel O, Arslan S. Serum beta 2-microglobulin as a biomarker in inflammatory bowel disease. World J Gastroenterol. 2014; 20(31):10916-10920.

27. Josson S, Nomura T, Lin JT, Huang WC, Wu D, Zhau HE, et al. $\beta 2$-microglobulin induces epithelial to mesenchymal transition and confers cancer lethality and bone metastasis in human cancer cells. Cancer Res. 2011; 71(7):2600-2610.

28. Li L, Dong M, Wang XG. The Implication and Significance of Beta 2 Microglobulin: A Conservative Multifunctional Regulator. Chin Med J (Engl). 2016; 129(4):448-455.

29. Juraschek SP, Coresh J, Inker LA, Levey AS, Köttgen A, Foster MC, et al. Comparison of serum concentrations of $\beta$-trace protein, $\beta 2$-microglobulin, cystatin $C$, and creatinine in the US population. Clin J Am Soc Nephrol. 2013; 8(4):584-592.

30. Wang HJ, Si QJ, Shi Y, Guo Y, Li Y, Wang YT. The prognostic values of beta-2 microglobulin for risks of cardiovascular events and mortality in the elderly patients with isolated systolic hypertension. $J$ Res Med Sci. 2018; 23:82.

31. Shi F, Sun L, Kaptoge S. Association of beta-2-microglobulin and cardiovascular events and mortality: A systematic review and meta-analysis. Atherosclerosis. 2021; 320:70-78.

32. Kawai K, Kawashima S, Miyazaki T, Tajiri E, Mori M, Kitazaki K, et al. Serum beta2-microglobulin concentration as a novel marker to distinguish levels of risk in acute heart failure patients. $\mathrm{J}$ Cardiol. 2010; 55(1):99-107.

33. Kohanpour MA, Sanavi S, Peeri M, Zare AH, Mirsepasi M. Effect of submaximal aerobic exercise in hypoxic conditions on proteinuria and hematuria in physically trained young men. Iran J Kidney Dis. 2012; 6(3):192-197. 
34. Hadzimuratovic E, Skrablin S, Hadzimuratovic A, Dinarevic SM. Postasphyxial renal injury in newborns as a prognostic factor of neurological outcome. J Matern Fetal Neonatal Med. 2014; 27(4):407-410.

35. McNicholas BA, Rezoagli E, Pham T, Madotto F, Guiard E, Fanelli V, et al. Impact of Early Acute Kidney Injury on Management and Outcome in Patients With Acute Respiratory Distress Syndrome: A Secondary Analysis of a Multicenter Observational Study. Crit Care Med. 2019; 47(9):1216-1225.

36. Wang F, Ran L, Qian C, Hua J, Luo Z, Ding M, et al. Epidemiology and Outcomes of Acute Kidney Injury in COVID-19 Patients with Acute Respiratory Distress Syndrome: A Multicenter Retrospective Study. Blood Purif. 2020:1-7.

37. Zhou XJ, Zhang X, Zhang J, Zhou L, Zhou TT, Zhang JW. Diagnostic value of growth differentiation factor-15 and $\beta 2$-microglobulin in children with congenital heart disease combined with chronic heart failure and its relationship with cardiac function. Eur Rev Med Pharmacol Sci. 2020; 24(15):80968103.

38. Dong XM, Cai R, Yang F, Zhang YY, Wang XG, Fu SL, et al. Predictive value of plasma $\beta 2-$ microglobulin on human body function and senescence. Eur Rev Med Pharmacol Sci. 2016; 20(11):2350-2356.

39. Stevens PE, Levin A. Evaluation and management of chronic kidney disease: synopsis of the kidney disease: improving global outcomes 2012 clinical practice guideline. Ann Intern Med. 2013; 158(11):825-830.

40. Ternavasio-de la Vega HG, Castaño-Romero F, Ragozzino S, Sánchez González R, Vaquero-Herrero MP, Siller-Ruiz M, et al. The updated Charlson comorbidity index is a useful predictor of mortality in patients with Staphylococcus aureus bacteraemia. Epidemiol Infect. 2018; 146(16):2122-2130.

41. Bou Chebl R, El Khuri C, Shami A, Rajha E, Faris N, Bachir R, et al. Serum lactate is an independent predictor of hospital mortality in critically ill patients in the emergency department: a retrospective study. Scand J Trauma Resusc Emerg Med. 2017; 25(1):69.

42. Demirel B. Lactate levels and pneumonia severity index are good predictors of in-hospital mortality in pneumonia. Clin Respir J. 2018; 12(3):991-995.

43. Sehgal IS, Agarwal R, Dhooria S, Prasad KT, Muthu V, Aggarwal AN. Risk stratification of acute respiratory distress syndrome using a PaO2: Fio2 threshold of $150 \mathrm{mmHg}$ : A retrospective analysis from an Indian intensive care unit. Lung India. 2020; 37(6):473-478.

44. Villar J, Pérez-Méndez L, Basaldúa S, Blanco J, Aguilar G, Toral D, et al. A risk tertiles model for predicting mortality in patients with acute respiratory distress syndrome: age, plateau pressure, and $\mathrm{P}(\mathrm{aO}(2)) / \mathrm{F}(\mathrm{IO}(2))$ at ARDS onset can predict mortality. Respir Care. 2011; 56(4):420-428.

\section{Tables}


Table 1

Demographic and Clinical Characteristics of Patients with ARDS

\begin{tabular}{|c|c|c|c|c|}
\hline $\begin{array}{l}\text { Clinical } \\
\text { characteristics }\end{array}$ & $\begin{array}{l}\text { Total ARDS } \\
(\mathrm{N}=257)\end{array}$ & $\begin{array}{l}\text { Survivors } \\
(n=161)\end{array}$ & $\begin{array}{l}\text { Non-Survivors } \\
(n=96)\end{array}$ & $P$ value \\
\hline Age (years) & $70(57,80)$ & $68(55,77)$ & $74(62,81)$ & 0.002 \\
\hline Male, n (\%) & $167(65.0)$ & $102(63.4)$ & $65(67.7)$ & 0.479 \\
\hline $\begin{array}{l}\text { Current smoker, } \\
\text { n (\%) }\end{array}$ & $107(41.6)$ & $69(42.9)$ & $38(39.6)$ & 0.607 \\
\hline $\mathrm{CCl}$ updated & $2(0,3)$ & $1(0,3)$ & $2(1,3)$ & $<0.001$ \\
\hline BMI & $24.3 \pm 4.6$ & $24.4 \pm 4.4$ & $24.3 \pm 5.0$ & 0.860 \\
\hline $\begin{array}{l}\text { Disorders of consciousness, } n \\
(\%)\end{array}$ & $60(23.3)$ & $33(20.5)$ & $27(28.1)$ & 0.162 \\
\hline Septic shock, n (\%) & $127(49.4)$ & $67(41.6)$ & $60(62.5)$ & 0.001 \\
\hline$\beta 2 M G(m g / L)$ & $4.6(2.9,8.5)$ & $3.8(2.5,6.5)$ & $6.2(4.1,12.3)$ & $<0.001$ \\
\hline $\operatorname{Scr}(\mu \mathrm{mol} / \mathrm{L})$ & $\begin{array}{l}113.0(67.4 \\
207.8)\end{array}$ & $\begin{array}{l}90.5(63.0 \\
190.8)\end{array}$ & $\begin{array}{l}139.4(92.3 \\
286.7)\end{array}$ & $<0.001$ \\
\hline $\operatorname{Ccr}(\mathrm{mL} / \mathrm{min})$ & $43.0(25.2,81.5)$ & $\begin{array}{l}55.9(29.8 \\
104.6)\end{array}$ & $33.2(18.6,57.9)$ & $<0.001$ \\
\hline BUN (mmol/L) & $11.3(6.1,17.8)$ & $9.1(4.9,15.6)$ & $15.4(10.2,25.0)$ & $<0.001$ \\
\hline AKI, n (\%) & $154(59.9)$ & $82(50.9)$ & $72(75.0)$ & $<0.001$ \\
\hline Albumin (g/L) & $26.3(23.4,30.1)$ & $\begin{array}{l}27.0(24.1 \\
31.0)\end{array}$ & $24.8(21.4,29.3)$ & $<0.001$ \\
\hline TBIL $(\mu \mathrm{mol} / \mathrm{L})$ & $20.8(13.1,31.6)$ & $\begin{array}{l}20.8(12.7 \\
31.0)\end{array}$ & $20.8(13.2,35.2)$ & 0.674 \\
\hline
\end{tabular}

Data are the mean $\pm \mathrm{SD}$, median (IQR), or $\mathrm{n}(\%)$. $P$ values comparing the Survivor and non-Survivor groups are from a 2-sample $t$-test, Mann-Whitney $U$ test, or $\chi^{2}$ test. Differences with values of $P<0.05$ were considered statistically significant.

${ }^{*} \chi^{2}$ test comparing the Survivor and non-Survivor groups. ${ }^{\dagger} \chi^{2}$ test comparing all subcategories.

Abbreviations: ARDS, acute respiratory disease syndrome; $\mathrm{CCl}$, Charlson comorbidity index; $\mathrm{BMI}$, body mass index; $\beta 2 M G$, $\beta 2$-microglobulin; Scr, serum creatinine; Ccr, creatinine clearance rate; BUN, blood urea nitrogen; AKI, acute kidney injury; TBIL, total bilirubin; ALT, alanine aminotransferase; NT-proBNP, $\mathrm{N}$-terminal pro-brain natriuretic peptide; cTnl, cardiac troponin I; FPG, fasting plasma glucose; WBC, white blood cell; CRP, C-reactive protein; $\mathrm{PCT}$, procalcitonin; $\mathrm{PT}$, prothrombin time; $\mathrm{PaO}_{2}$, partial pressure of arterial oxygen; $\mathrm{FiO}_{2}$, fraction of inspired oxygen; Mild, $200 \mathrm{mmHg}<\mathrm{PaO}_{2} / \mathrm{FiO}_{2}$ ratio $\leq 300$ $\mathrm{mmHg}$; Moderate, $100 \mathrm{mmHg}<\mathrm{PaO}_{2} / \mathrm{FiO}_{2}$ ratio $\leq 200 \mathrm{mmHg}$; Severe, $\mathrm{PaO}_{2} / \mathrm{FiO}_{2}$ ratio $\leq 100 \mathrm{mmHg}$; MV, mechanical ventilation; APACHE, Acute Physiology and Chronic Health Evaluation; SOFA, Sequential Organ Failure Assessment; SD, standard deviation; IQR, interquartile range. 


\begin{tabular}{|c|c|c|c|c|}
\hline $\begin{array}{l}\text { Clinical } \\
\text { characteristics }\end{array}$ & $\begin{array}{l}\text { Total ARDS } \\
(\mathrm{N}=257)\end{array}$ & $\begin{array}{l}\text { Survivors } \\
(n=161)\end{array}$ & $\begin{array}{l}\text { Non-Survivors } \\
(\mathrm{n}=96)\end{array}$ & $P$ value \\
\hline $\operatorname{ALT}(\mathrm{U} / \mathrm{L})$ & $31.0(18.5,66.4)$ & $\begin{array}{l}29.7(17.8, \\
59.6)\end{array}$ & $32.9(18.8,84.5)$ & 0.337 \\
\hline \multirow[t]{2}{*}{ NT-proBNP (pg/mL) } & 1830.6 & 1084.0 & 2863.0 & $<0.001$ \\
\hline & $(522.3,5176.3)$ & $(318.3,4112.5)$ & $(1446.0,7080.1)$ & \\
\hline cTnl (ng/mL) & $0.10(0.04,0.41)$ & $\begin{array}{l}0.06(0.02 \\
0.29)\end{array}$ & $0.17(0.06,0.56)$ & 0.001 \\
\hline Acute myocardial injury, $\mathrm{n}(\%)$ & $127(49.4)$ & $59(61.5)$ & $68(42.2)$ & 0.003 \\
\hline FPG (mmol/L) & $8.6(6.6,11.4)$ & $8.1(6.5,10.6)$ & $8.9(7.1,12.4)$ & 0.124 \\
\hline WBC $\left(\times 10^{9} / \mathrm{L}\right)$ & $16.5(11.7,21.3)$ & $\begin{array}{l}16.3(11.7 \\
21.0)\end{array}$ & $16.9(13.1,23.1)$ & 0.489 \\
\hline $\mathrm{CPR}(\mathrm{mg} / \mathrm{L})$ & $120(98,120)$ & $120(102,120)$ & $120(86,120)$ & 0.595 \\
\hline PCT (ng/mL) & $5.6(0.7,18.8)$ & $3.5(0.4,15.9)$ & $6.3(1.9,24.6)$ & 0.008 \\
\hline PT (s) & $13.9(12.6,16.2)$ & $\begin{array}{l}13.5(12.2 \\
15.6)\end{array}$ & $15.0(13.3,17.4)$ & 0.001 \\
\hline Lactic acid (mmol/L) & $1.8(1.3,2.7)$ & $1.6(1.1,2.3)$ & $2.3(1.5,4.0)$ & $<0.001$ \\
\hline $\mathrm{PaO}_{2} / \mathrm{FiO}_{2}$ ratio & $157(105,199)$ & $172(117,208)$ & $134(81,178)$ & $\begin{array}{l}< \\
0.001^{*}\end{array}$ \\
\hline Mild, n (\%) & $63(24.5)$ & $48(29.8)$ & $15(15.6)$ & $\begin{array}{l}<.001^{\dagger} \\
0\end{array}$ \\
\hline Moderate, n (\%) & $131(51.0)$ & $86(53.4)$ & $45(46.9)$ & \\
\hline Severe, n (\%) & $63(24.5)$ & $27(16.8)$ & $36(37.5)$ & \\
\hline
\end{tabular}

Data are the mean $\pm \mathrm{SD}$, median (IQR), or $\mathrm{n}(\%)$. $P$ values comparing the Survivor and non-Survivor groups are from a 2-sample $t$-test, Mann-Whitney $U$ test, or $\chi^{2}$ test. Differences with values of $P<0.05$ were considered statistically significant.

${ }^{*} \chi^{2}$ test comparing the Survivor and non-Survivor groups. ${ }^{\dagger} \chi^{2}$ test comparing all subcategories.

Abbreviations: ARDS, acute respiratory disease syndrome; $\mathrm{CCl}$, Charlson comorbidity index; $\mathrm{BMI}$, body mass index; $\beta 2 M G$, $\beta 2$-microglobulin; Scr, serum creatinine; Ccr, creatinine clearance rate; BUN, blood urea nitrogen; AKI, acute kidney injury; TBIL, total bilirubin; ALT, alanine aminotransferase; NT-proBNP, $\mathrm{N}$-terminal pro-brain natriuretic peptide; cTnl, cardiac troponin l; FPG, fasting plasma glucose; WBC, white blood cell; CRP, C-reactive protein; $\mathrm{PCT}$, procalcitonin; $\mathrm{PT}$, prothrombin time; $\mathrm{PaO}_{2}$, partial pressure of arterial oxygen; $\mathrm{FiO}_{2}$, fraction of inspired oxygen; Mild, $200 \mathrm{mmHg}<\mathrm{PaO}_{2} / \mathrm{FiO}_{2}$ ratio $\leq 300$ $\mathrm{mmHg}$; Moderate, $100 \mathrm{mmHg}<\mathrm{PaO}_{2} / \mathrm{FiO}_{2}$ ratio $\leq 200 \mathrm{mmHg}$; Severe, $\mathrm{PaO}_{2} / \mathrm{FiO}_{2}$ ratio $\leq 100 \mathrm{mmHg}$; MV, mechanical ventilation; APACHE, Acute Physiology and Chronic Health Evaluation; SOFA, Sequential Organ Failure Assessment; SD, standard deviation; IQR, interquartile range. 


\begin{tabular}{|c|c|c|c|c|}
\hline $\begin{array}{l}\text { Clinical } \\
\text { characteristics }\end{array}$ & $\begin{array}{l}\text { Total ARDS } \\
(\mathrm{N}=257)\end{array}$ & $\begin{array}{l}\text { Survivors } \\
(\mathrm{n}=161)\end{array}$ & $\begin{array}{l}\text { Non-Survivors } \\
(\mathrm{n}=96)\end{array}$ & $P$ value \\
\hline Duration of MV (days) & $8(5,16)$ & $8(5,17)$ & $8(5,14)$ & 0.959 \\
\hline APACHE II score & $24(19,30)$ & $22(17,28)$ & $27(21,32)$ & $<0.001$ \\
\hline SOFA score & $8(5,11)$ & $7(4,10)$ & $9(7,12)$ & $<0.001$ \\
\hline \multicolumn{5}{|c|}{$\begin{array}{l}\text { Data are the mean } \pm \text { SD, median }(\mathrm{IQR}) \text {, or } n(\%) \text {. } P \text { values comparing the Survivor and non-Survivor } \\
\text { groups are from a } 2 \text {-sample } t \text {-test, Mann-Whitney } U \text { test, or } \chi^{2} \text { test. Differences with values of } P<0.05 \\
\text { were considered statistically significant. }\end{array}$} \\
\hline \multicolumn{5}{|c|}{${ }^{*} \chi^{2}$ test comparing the Survivor and non-Survivor groups. ${ }^{\dagger} \chi^{2}$ test comparing all subcategories. } \\
\hline \multicolumn{5}{|c|}{ 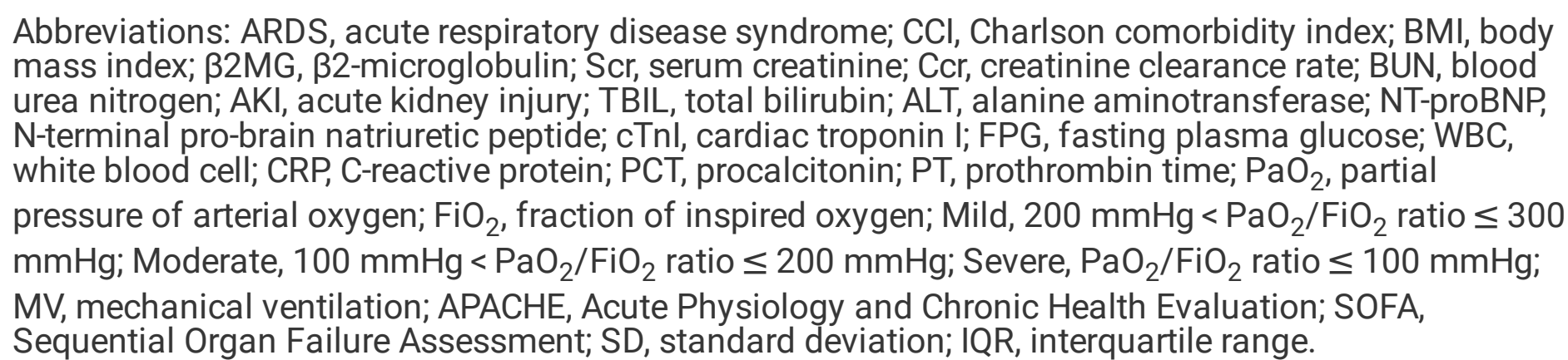 } \\
\hline
\end{tabular}


Table 2

Univariate and Multivariate Survival Analysis of the 28-Day Mortality Risk in Patients with ARDS

\begin{tabular}{|c|c|c|c|c|}
\hline Clinical characteristics & $\begin{array}{l}\text { Univariate HR } \\
(95 \% \mathrm{Cl})\end{array}$ & $\begin{array}{l}P \\
\text { value }\end{array}$ & $\begin{array}{l}\text { Multivariate HR } \\
(95 \% \mathrm{Cl})\end{array}$ & $P$ value \\
\hline$\beta 2 M G(m g / L)$ & $\begin{array}{l}1.096(1.064 \\
1.128)\end{array}$ & $<0.001$ & $1.050(1.012,1.091)$ & 0.010 \\
\hline Age (years) & $\begin{array}{l}1.019(1.005 \\
1.033)\end{array}$ & 0.008 & $1.004(0.987,1.021)$ & 0.652 \\
\hline $\mathrm{CCl}$ updated & $\begin{array}{l}1.251(1.127, \\
1.388)\end{array}$ & $<0.001$ & $1.150(1.017,1.300)$ & 0.025 \\
\hline $\begin{array}{l}\text { Disorders of consciousness, } n \\
(\%)\end{array}$ & $\begin{array}{l}1.557(0.998 \\
2.431)\end{array}$ & 0.051 & $\begin{array}{l}1.099(0.669 \\
1.804)\end{array}$ & 0.709 \\
\hline Septic shock, n (\%) & $\begin{array}{l}2.043 \text { (1.351, } \\
3.090)\end{array}$ & 0.001 & $1.145(0.717,1.829)$ & 0.570 \\
\hline Albumin $(\mathrm{g} / \mathrm{L})$ & $\begin{array}{l}0.928(0.893 \\
0.964)\end{array}$ & $<0.001$ & $0.964(0.924,1.006)$ & 0.093 \\
\hline cTnl (ng/mL) & $\begin{array}{l}1.032(0.937 \\
1.137)\end{array}$ & 0.522 & $1.204(0.894,1.173)$ & 0.733 \\
\hline РCT (ng/mL) & $\begin{array}{l}1.020(1.002 \\
1.038)\end{array}$ & 0.026 & $1.005(0.986,1.025)$ & 0.602 \\
\hline PT (s) & $\begin{array}{l}1.018(1.003 \\
1.033)\end{array}$ & 0.020 & $1.006(0.989,1.023)$ & 0.524 \\
\hline Lactic acid (mmol/L) & $\begin{array}{l}1.104(1.062 \\
1.146)\end{array}$ & $<0.001$ & $1.045(1.001,1.092)$ & 0.047 \\
\hline $\mathrm{PaO}_{2} / \mathrm{FiO}_{2}$ ratio & $\begin{array}{l}0.994(0.991 \\
0.998)\end{array}$ & 0.001 & $0.996(0.992,1.000)$ & 0.028 \\
\hline Male, n (\%) & $\begin{array}{l}1.143(0.745, \\
1.753)\end{array}$ & 0.542 & & \\
\hline
\end{tabular}

A Cox proportional hazards analysis was performed. Data are the $\mathrm{HR}(95 \% \mathrm{Cl})$. Adjusted for age, updated $\mathrm{CCl}$, disorders of consciousness, septic shock, albumin, cTnl, procalcitonin, prothrombin time, lactic acid, and $\mathrm{PaO}_{2} / \mathrm{FiO}_{2}$ ratio. Differences with values of $P<0.05$ were considered statistically significant.

Abbreviations: ARDS, acute respiratory disease syndrome; $\beta 2 \mathrm{MG}, \beta 2$-microglobulin; $\mathrm{CCl}$, Charlson comorbidity index; cTnl cardiac troponin I; PCT, procalcitonin; PT, prothrombin time; $\mathrm{PaO}_{2}$, partial pressure of arterial oxygen; $\mathrm{FiO}_{2}$, fraction of inspired oxygen; $\mathrm{BMI}$, body mass index; $\mathrm{Scr}$, serum creatinine; $\mathrm{Ccr}$, creatinine clearance rate; BUN, blood urea nitrogen; AKI, acute kidney injury; TBIL, total bilirubin; ALT, alanine aminotransferase; NT-proBNP, N-terminal pro-brain natriuretic peptide; FPG, fasting plasma glucose; WBC, white blood cell; CRP, C-reactive protein; APACHE, Acute Physiology and Chronic Health Evaluation; SOFA, Sequential Organ Failure Assessment; HR, hazard ratio; $\mathrm{Cl}$, confidence interval. 


\begin{tabular}{|c|c|c|c|c|}
\hline Clinical characteristics & $\begin{array}{l}\text { Univariate HR } \\
(95 \% \mathrm{Cl})\end{array}$ & $\begin{array}{l}P \\
\text { value }\end{array}$ & $\begin{array}{l}\text { Multivariate HR } \\
(95 \% \mathrm{Cl})\end{array}$ & $P$ value \\
\hline BMI & $\begin{array}{l}0.988(0.943 \\
1.034)\end{array}$ & 0.604 & & \\
\hline Current smoker, n (\%) & $\begin{array}{l}0.906(0.602 \\
1.364)\end{array}$ & 0.637 & & \\
\hline $\operatorname{Scr}(\mu \mathrm{mol} / \mathrm{L})$ & $\begin{array}{l}1.002(1.001 \\
1.003)\end{array}$ & 0.001 & & \\
\hline $\operatorname{Ccr}(\mathrm{mL} / \mathrm{min})$ & $\begin{array}{l}0.986(0.979 \\
0.992)\end{array}$ & $<0.001$ & & \\
\hline BUN (mmol/L) & $\begin{array}{l}1.035(1.022 \\
1.048)\end{array}$ & $<0.001$ & & \\
\hline AKI, n (\%) & $\begin{array}{l}2.503(1.576 \\
3.796)\end{array}$ & $<0.001$ & & \\
\hline TBIL $(\mu \mathrm{mol} / \mathrm{L})$ & $\begin{array}{l}1.002(1.000 \\
1.003)\end{array}$ & 0.115 & & \\
\hline $\operatorname{ALT}(U / L)$ & $\begin{array}{l}1.000(1.000 \\
1.001)\end{array}$ & 0.242 & & \\
\hline NT-proBNP (pg/mL) & $\begin{array}{l}1.000(1.000 \\
1.000)\end{array}$ & 0.207 & & \\
\hline $\mathrm{FPG}(\mathrm{mmol} / \mathrm{L})$ & $\begin{array}{l}1.021(0.980 \\
1.064)\end{array}$ & 0.312 & & \\
\hline WBC $\left(\times 10^{9} / \mathrm{L}\right)$ & $\begin{array}{l}1.007(0.984 \\
1.030)\end{array}$ & 0.549 & & \\
\hline CRP (mg/L) & $\begin{array}{l}0.998 \\
1.003)\end{array}$ & 0.486 & & \\
\hline APACHE II score & $\begin{array}{l}1.056(1.032 \\
1.081)\end{array}$ & $<0.001$ & & \\
\hline
\end{tabular}

A Cox proportional hazards analysis was performed. Data are the $\mathrm{HR}(95 \% \mathrm{Cl})$. Adjusted for age, updated $\mathrm{CCl}$, disorders of consciousness, septic shock, albumin, cTnl, procalcitonin, prothrombin time, lactic acid, and $\mathrm{PaO}_{2} / \mathrm{FiO}_{2}$ ratio. Differences with values of $P<0.05$ were considered statistically significant.

Abbreviations: ARDS, acute respiratory disease syndrome; $\beta 2 \mathrm{MG}, \beta 2$-microglobulin; $\mathrm{CCl}$, Charlson comorbidity index; cTnl cardiac troponin I; PCT, procalcitonin; PT, prothrombin time; $\mathrm{PaO}_{2}$, partial pressure of arterial oxygen; $\mathrm{FiO}_{2}$, fraction of inspired oxygen; $\mathrm{BMI}$, body mass index; $\mathrm{Scr}$, serum creatinine; $\mathrm{Ccr}$, creatinine clearance rate; BUN, blood urea nitrogen; AKI, acute kidney injury; TBIL, total bilirubin; ALT, alanine aminotransferase; NT-proBNP, N-terminal pro-brain natriuretic peptide; FPG, fasting plasma glucose; WBC, white blood cell; CRP, C-reactive protein; APACHE, Acute Physiology and Chronic Health Evaluation; SOFA, Sequential Organ Failure Assessment; HR, hazard ratio; $\mathrm{Cl}$, confidence interval. 


\begin{tabular}{|c|c|c|c|c|}
\hline Clinical characteristics & $\begin{array}{l}\text { Univariate HR } \\
(95 \% \mathrm{Cl})\end{array}$ & $\begin{array}{l}P \\
\text { value }\end{array}$ & $\begin{array}{l}\text { Multivariate HR } \\
(95 \% \mathrm{Cl})\end{array}$ & $P$ value \\
\hline SOFA score & $\begin{array}{l}1.096(1.050 \\
1.143)\end{array}$ & $<0.001$ & & \\
\hline \multicolumn{5}{|c|}{$\begin{array}{l}\text { A Cox proportional hazards analysis was performed. Data are the } \mathrm{HR}(95 \% \mathrm{Cl}) \text {. Adjusted for age, } \\
\text { updated } \mathrm{CCl} \text {, disorders of consciousness, septic shock, albumin, cTnl, procalcitonin, prothrombin time, } \\
\text { lactic acid, and } \mathrm{PaO}_{2} / \mathrm{FiO}_{2} \text { ratio. Differences with values of } P<0.05 \text { were considered statistically } \\
\text { significant. }\end{array}$} \\
\hline \multicolumn{5}{|c|}{$\begin{array}{l}\text { Abbreviations: ARDS, acute respiratory disease syndrome; } \beta 2 \mathrm{MG}, \beta 2 \text {-microglobulin; } \mathrm{CCl} \text {, Charlson } \\
\text { comorbidity index; cTnl cardiac troponin I; PCT, procalcitonin; PT, prothrombin time; } \mathrm{PaO}_{2} \text {, partial } \\
\text { pressure of arterial oxygen; } \mathrm{FiO}_{2} \text {, fraction of inspired oxygen; BMI, body mass index; } \mathrm{Scr} \text {, serum } \\
\text { creatinine; Ccr, creatinine clearance rate; } \mathrm{BUN} \text {, blood urea nitrogen; } \mathrm{AKI} \text {, acute kidney injury; TBIL, total } \\
\text { bilirubin; ALT, alanine aminotransferase; NT-proBNP, N-terminal pro-brain natriuretic peptide; FPG, } \\
\text { fasting plasma glucose; WBC, white blood cell; CRP, C-reactive protein; APACHE, Acute Physiology and } \\
\text { Chronic Health Evaluation; SOFA, Sequential Organ Failure Assessment; HR, hazard ratio; Cl, } \\
\text { confidence interval. }\end{array}$} \\
\hline
\end{tabular}


Table 3

Spearman Rank Correlation Between $32 \mathrm{MG}$ and Basic Variables in Patients with ARDS

\begin{tabular}{|lll|}
\hline Variables & Correlation coefficient & Pvalue \\
\hline Age $($ years $)$ & 0.243 & $<0.001$ \\
\hline Male, $\mathrm{n}(\%)$ & -0.029 & 0.649 \\
\hline BMI & 0.001 & 0.989 \\
\hline Disturbance of consciousness, $\mathrm{n}(\%)$ & 0.160 & 0.010 \\
\hline Septic shock, $\mathrm{n}(\%)$ & 0.277 & $<0.001$ \\
\hline CCl updated & 0.234 & $<0.001$ \\
\hline Current smoker, $\mathrm{n}(\%)$ & -0.037 & 0.559 \\
\hline Scr $(\mu \mathrm{mol} / \mathrm{L})$ & 0.814 & $<0.001$ \\
\hline Ccr $(\mathrm{mL} / \mathrm{min})$ & -0.810 & $<0.001$ \\
\hline BUN $(\mathrm{mmol} / \mathrm{L})$ & 0.723 & $<0.001$ \\
\hline AKI, $\mathrm{n}(\%)$ & 0.681 & $<0.001$ \\
\hline Albumin $(\mathrm{g} / \mathrm{L})$ & -0.235 & $<0.001$ \\
\hline TBIL $(\mu \mathrm{mol} / \mathrm{L})$ & 0.082 & 0.190 \\
\hline ALT $(\mathrm{U} / \mathrm{L})$ & -0.063 & 0.312 \\
\hline cTnl $(\mathrm{ng} / \mathrm{mL})$ & 0.364 & $<0.001$ \\
\hline NT-proBNP $(\mathrm{pg} / \mathrm{mL})$ & 0.563 & $<0.001$ \\
\hline NT-proBNP* $(\mathrm{pg} / \mathrm{mL})$ & 0.338 & 0.001 \\
\hline LVEF $(\%)$ & -0.294 & 0.068 \\
\hline FPG $(\mathrm{mmol} / \mathrm{L})$ & -0.009 & $<.136$ \\
\hline WBC $\left(\times 10^{9} / \mathrm{L}\right)$ & 0.114 & 0.001 \\
\hline CRP $(\mathrm{mg} / \mathrm{L})$ & & 0.001 \\
\hline
\end{tabular}

Abbreviations: $\beta 2 M G, \beta 2$-microglobulin; ARDS, acute respiratory disease syndrome; BMI, body mass index; $\mathrm{CCl}$, Charlson comorbidity index; $\mathrm{Scr}$, serum creatinine; $\mathrm{Ccr}$, creatinine clearance rate; $\mathrm{BUN}$, blood urea nitrogen; AKI, acute kidney injury; TBIL, total bilirubin; ALT, alanine aminotransferase; cTnl, cardiac troponin I; NT-proBNP, N-terminal pro-brain natriuretic peptide; NT-proBNP*, in the group with Ccr of $>60 \mathrm{~mL} / \mathrm{min}$; LVEF, left ventricular ejection fraction; FPG, fasting plasma glucose; WBC, white blood cell; CRP, C-reactive protein; CRP ${ }^{*}$, CRP level of < $120 \mathrm{mg} / \mathrm{L}$; PCT, procalcitonin; PT, prothrombin time; $\mathrm{PaO}_{2}$, partial pressure of arterial oxygen; $\mathrm{FiO}_{2}$, fraction of inspired oxygen; APACHE, Acute Physiology and Chronic Health Evaluation; SOFA, Sequential Organ Failure Assessment. 


\begin{tabular}{|c|c|c|}
\hline Variables & Correlation coefficient & $P$ value \\
\hline $\mathrm{CRP}^{\star}(\mathrm{mg} / \mathrm{L})$ & 0.562 & $<0.001$ \\
\hline PCT (ng/mL) & 0.421 & $<0.001$ \\
\hline PT (s) & 0.201 & 0.002 \\
\hline Lactic acid (mmol/L) & 0.187 & 0.003 \\
\hline $\mathrm{PaO}_{2} / \mathrm{FiO}_{2}$ ratio & -0.165 & 0.008 \\
\hline APACHE II score & 0.517 & $<0.001$ \\
\hline SOFA score & 0.566 & $<0.001$ \\
\hline \multicolumn{3}{|c|}{ 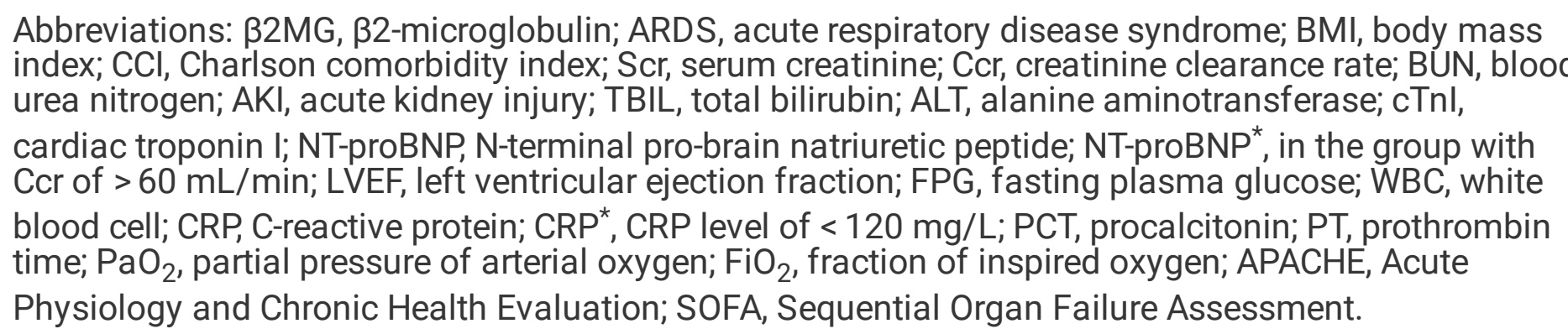 } \\
\hline
\end{tabular}

\section{Figures}




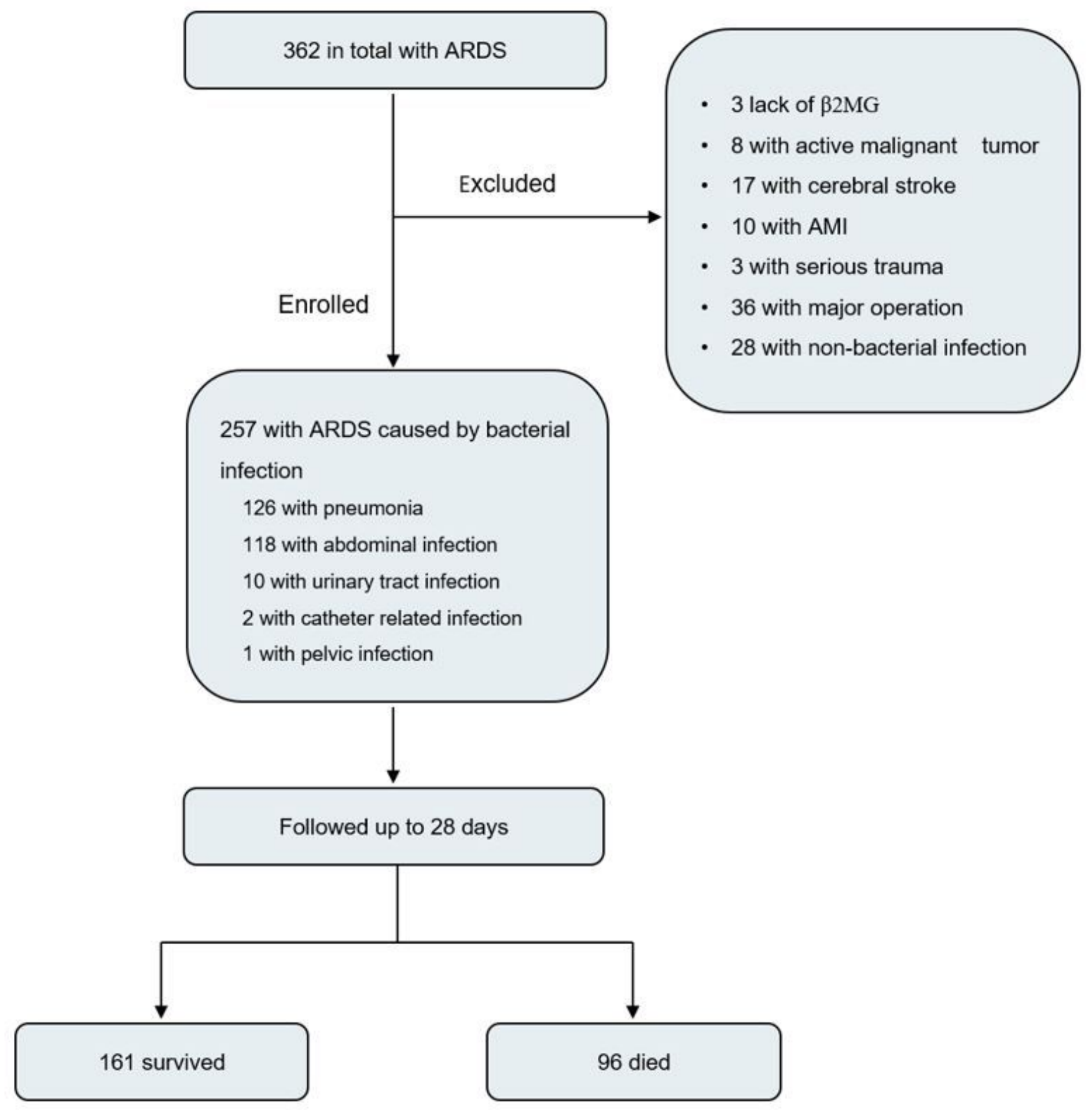

\section{Figure 1}

Flow chart of the patient enrollment and outcomes in this study. Abbreviations: ARDS, acute respiratory disease syndrome; $\mathrm{AMI}$, acute myocardial infarction; $\beta 2 \mathrm{MG}, \beta 2$-microglobulin. 


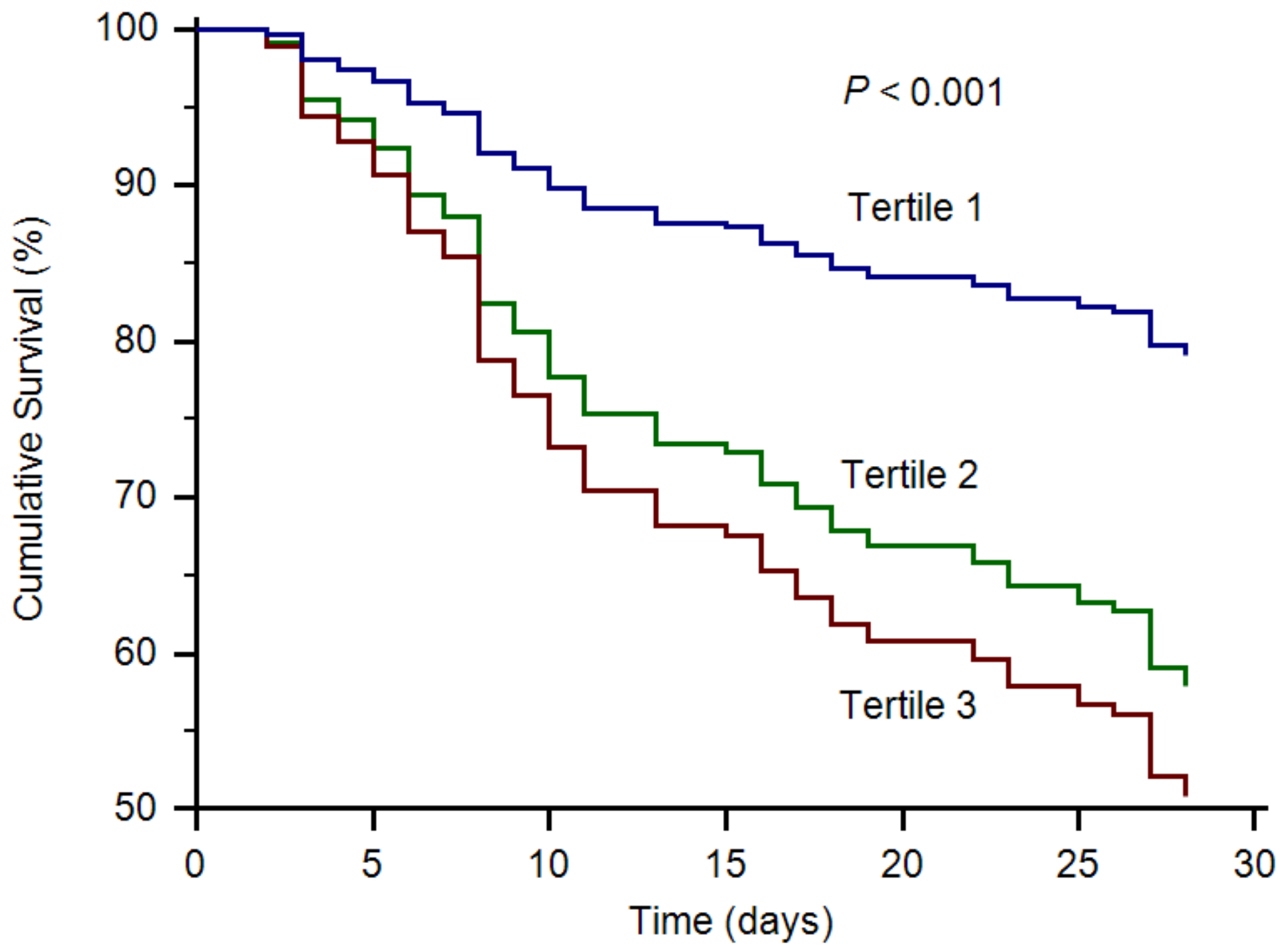

Figure 2

Survival curves of patients with ARDS stratified by $\beta 2 M G$ tertile. Data were adjusted for age, updated $\mathrm{CCl}$, disorders of consciousness, septic shock, albumin level, cTnl level, PCT level, PT, lactic acid level, and $\mathrm{PaO} 2 / \mathrm{FiO} 2$ ratio. Tertile 1, $\beta 2 \mathrm{MG}<3.5 \mathrm{mg} / \mathrm{L} ;$ Tertile 2, $\beta 2 \mathrm{MG}=3.5-6.5 \mathrm{mg} / \mathrm{L} ;$ Tertile 3, $\beta 2 \mathrm{MG}>6.5 \mathrm{mg} / \mathrm{L}$; HR: $1.482 ; 95 \% \mathrm{Cl}: 1.069-2.054 ; \mathrm{P}=0.018$ Abbreviations: ARDS: acute respiratory disease syndrome; $\beta 2 M G, \beta 2$-microglobulin; $\mathrm{CCl}$, Charlson comorbidity index; $\mathrm{CTnl}$, cardiac troponin I; PCT, procalcitonin; PT, prothrombin time; $\mathrm{PaO} 2$, partial pressure of arterial oxygen; FiO2, fraction of inspired oxygen. 


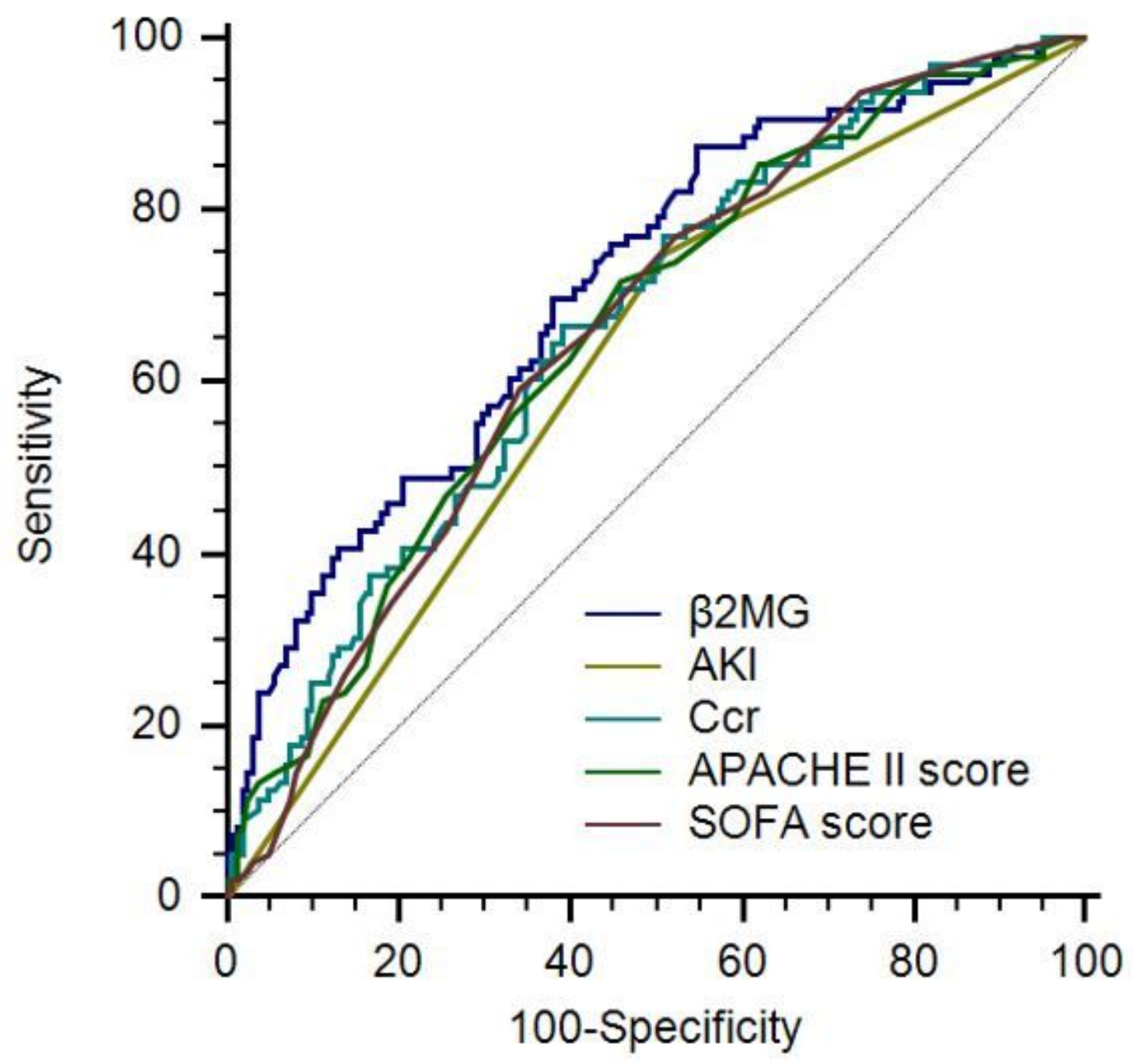

\begin{tabular}{lcccccc}
\hline Variables & Best cutoff & Sensitivity & Specificity & AUC $(95 \% \mathrm{CI})$ & $P$ Value & $P$ Value \\
\hline B2MG $(\mathrm{mg} / \mathrm{L})$ & $>4.0$ & 76.0 & 55.3 & $0.711(0.652-0.766)$ & $<0.001$ & \\
AKI & + & 75.0 & 49.1 & $0.620(0.558-0.680)$ & $<0.001$ & 0.001 \\
Ccr & $\leq 42.1$ & 66.7 & 60.9 & $0.665(0.604-0.723)$ & $<0.001$ & 0.032 \\
APACHE II Score & $>22$ & 71.9 & 54.0 & $0.661(0.599-0.718)$ & $<0.001$ & 0.153 \\
SOFA Score & $>8$ & 59.4 & 65.8 & $0.659(0.598-0.717)$ & $<0.001$ & 0.114 \\
\hline
\end{tabular}

Figure 3

Prediction of 28-day mortality in patients with ARDS. $\beta 2 M G$ showed a diagnostic accuracy for mortality screening that is superior to AKI $(P=0.001)$ and $\operatorname{Ccr}(P=0.032)$ and not inferior to the APACHE II Score ( $P$ $=0.153)$ and SOFA Score $(P=0.114) .{ }^{*}$ Comparing between $\beta 2 M G$ and other variables. Abbreviations: ARDS, acute respiratory disease syndrome; ROC, receiver operating characteristic; AUC, area under curve; $\beta 2 M G, \beta 2$-microglobulin; AKI, acute kidney injury; $C c r$, creatinine clearance rate; APACHE, Acute Physiology and Chronic Health Evaluation; SOFA, Sequential Organ Failure Assessment. 